\title{
Effect of Polyphenols on Cognitive Function: Evidence from Population-Based Studies and Clinical Trials
}

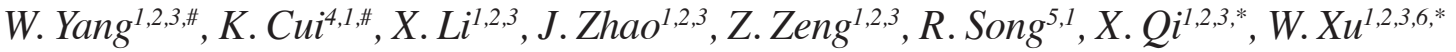

1. Department of Epidemiology and Biostatistics, School of Public Health, Tianjin Medical University, Tianjin, China; 2. Tianjin Key Laboratory of Environment, Nutrition and Public Health, Tianjin, China; 3. Center for International Collaborative Research on Environment, Nutrition and Public Health, Tianjin, China; 4. Department of Respiratory and Critical Care Medicine, The Fifth People's Hospital of Ganzhou, Ganzhou Institute of Respiratory Diseases, Ganzhou, Jiangxi, China; 5. Shandong Provincial Clinical Research Center for Emergency and Critical Care Medicine, Institute of Emergency and Critical Care Medicine of Shandong University, Chest Pain Center, Qilu Hospital of Shandong University, Jinan, Shandong, China; 6. Aging Research Center, Department of Neurobiology, Care Sciences and Society, Karolinska Institutet, Stockholm, Sweden; \# Wenzhe Yang and Kaiwang Cui contributed equally as the first authors

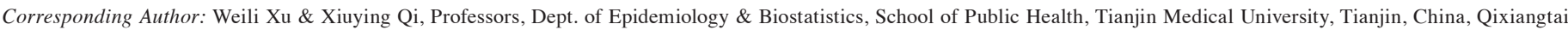

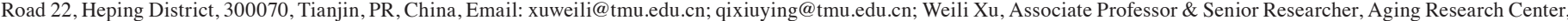
Karolinska Institutet, Tomtebodavägen 18A Floor 10, SE-171 65 Solna, Stockholm, Sweden, Phone: +46 8524 858 26; Email: weili.xu@ki.se

\begin{abstract}
Due to progressive population aging, a new dementia case occurs at every 3 seconds, placing a heavy burden of disease. Identifying potential risk or preventive factors is emphasized owing to a lack of effective treatment for dementia. There has been emerging evidence on the link of certain dietary components, particularly polyphenols, to brain wellness and cognitive outcomes. Findings from animal and in vitro studies appear more consistent and conclusive. However, such an association has not been investigated in depth in human beings. In this review, we examined studies on the effect of dietary polyphenols (including flavonoids, curcumin, and resveratrol) on cognitive function. Intervention in early stages of dementia/Alzheimer's disease might be a target to slow down age-related cognitive decline before disease onset. We summarized 28 epidemiological studies ( 8 cross-sectional and 20 cohort studies) and 55 trials in this review. Preliminary evidence from epidemiological data provides the necessity for intervention trials, even though the measures of polyphenol intake tend to be less precise. Clinical trials are in favor of the role of some polyphenols in benefiting specific domains of cognition. This review also describes the divergence of results and current limitations of research in this field.
\end{abstract}

Key words: Polyphenols, nutrition, cognitive decline, dementia, prevention.

\section{Introduction}

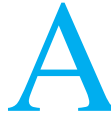
$s$ standards in health care have improved enormously, the lifespan of humanity everywhere is extended, subsequently bringing a higher incidence of aging-related diseases, especially among people over 65 years. Dementia and Alzheimer's disease (AD), as the common neurodegenerative disorders, impact advanced nervous activities in the brain, which in return causes memory decay and disturbances in reasoning, communication, and executive functions $(1,2)$. Therefore, dementing disorders place a heavy burden on not only patients themselves but their families and society in general, with one new case every 3 seconds worldwide (3). Unfortunately, there is a lack of effective cures for dementia. Therefore, it is critical to maintain or improve Received July 27, 2021 brain health to prevent dementia occurrence for general and high-risk population by modifiable factors.

Healthy lifestyle changes, particularly in nutrition patterns, have emerged as a strategy to reduce the burden of aging and age-related diseases. There are a large number of plant-derived components that have broad-ranging beneficial effects on health, and the class of phytochemicals called polyphenols may confer neuroprotective benefits $(4,5)$. In this context, polyphenol consumption has been proposed to prevent cognitive decline. A growing body of evidence coming from animal and in vitro studies has indicated that polyphenols may play an active role in cognitive function $(6,7)$. However, the effects of polyphenols on human brain have not been investigated in depth. Furthermore, clinical studies on the treatment of polyphenols for dementia or $\mathrm{AD}$, in which there have been already major neuropathology and a substantial loss of neurons in brain preceding so that it is challenging to reverse the damage (8), have revealed unsatisfactory efficacy $(9,10)$ and thereby the potential role of polyphenols in the prevention of dementia is highlighted. In the current review, we provide an overview of the existing data regarding the potential protective effects of polyphenols on cognitive health, especially in the context of populations at a high risk for dementia, such as the elderly and those with mild cognitive impairment (MCI). We also discuss the limitation of current data and challenges for future research.

\section{Polyphenols}

Polyphenols represent a wide variety of bioactive phytochemicals found in certain foods and beverages, such as fruits, vegetables, herbs, chocolate, coffee, green and black tea, beer, and red wines (11). Based on chemical structures, these compounds are divided into several subclasses: flavonoids, stilbenes, phenolic acids, and lignans (11). Polyphenols have been reported to possess antitumor, anti-inflammatory, antioxidant, anti-thrombotic, and antibacteria activities $(12,13)$, which contribute to various healthrelated benefits, including being against the progression of cardiovascular disease, diabetes, and cancer $(11,13)$. Considering that neurodegenerative diseases share certain 1190 


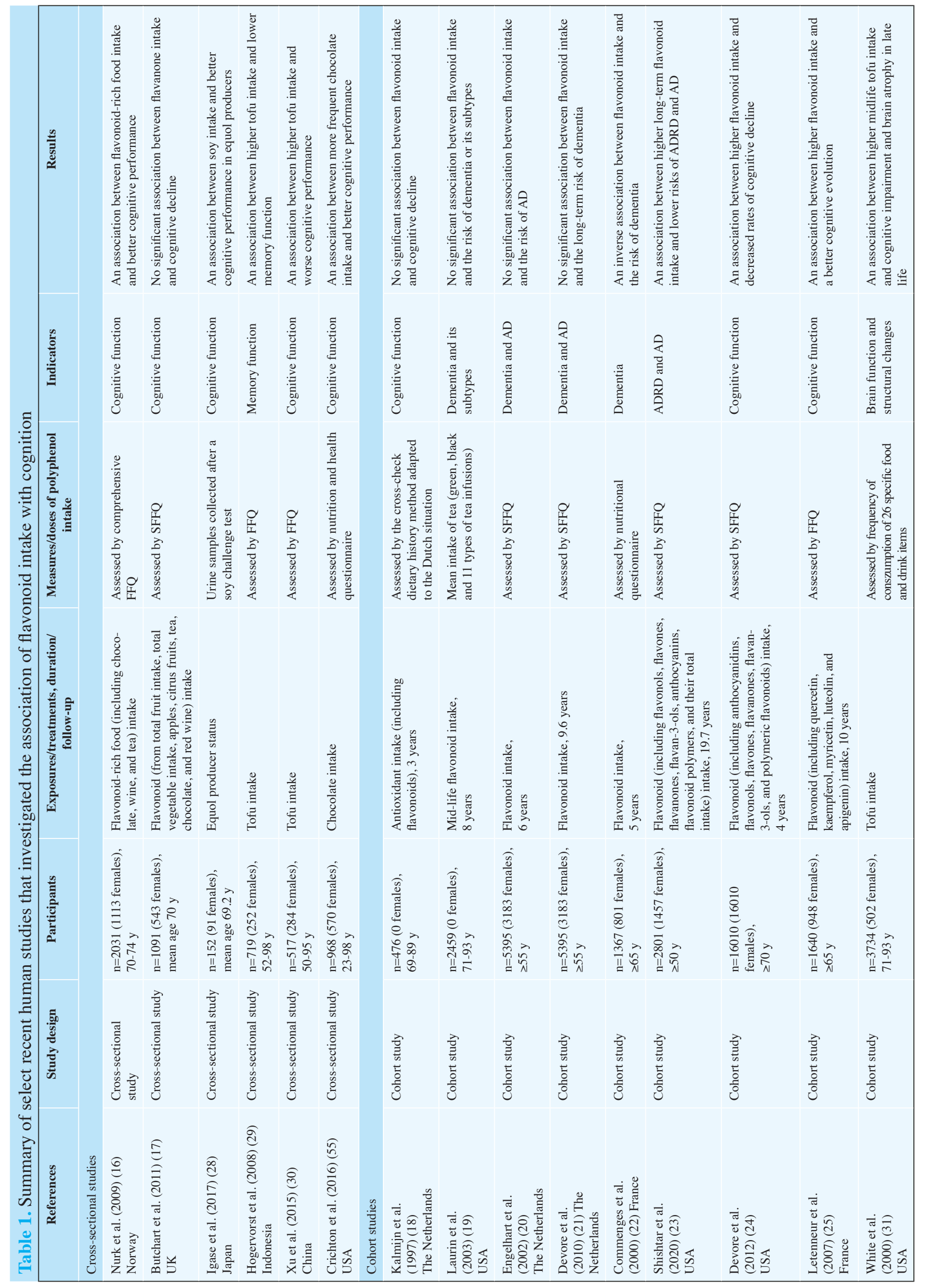




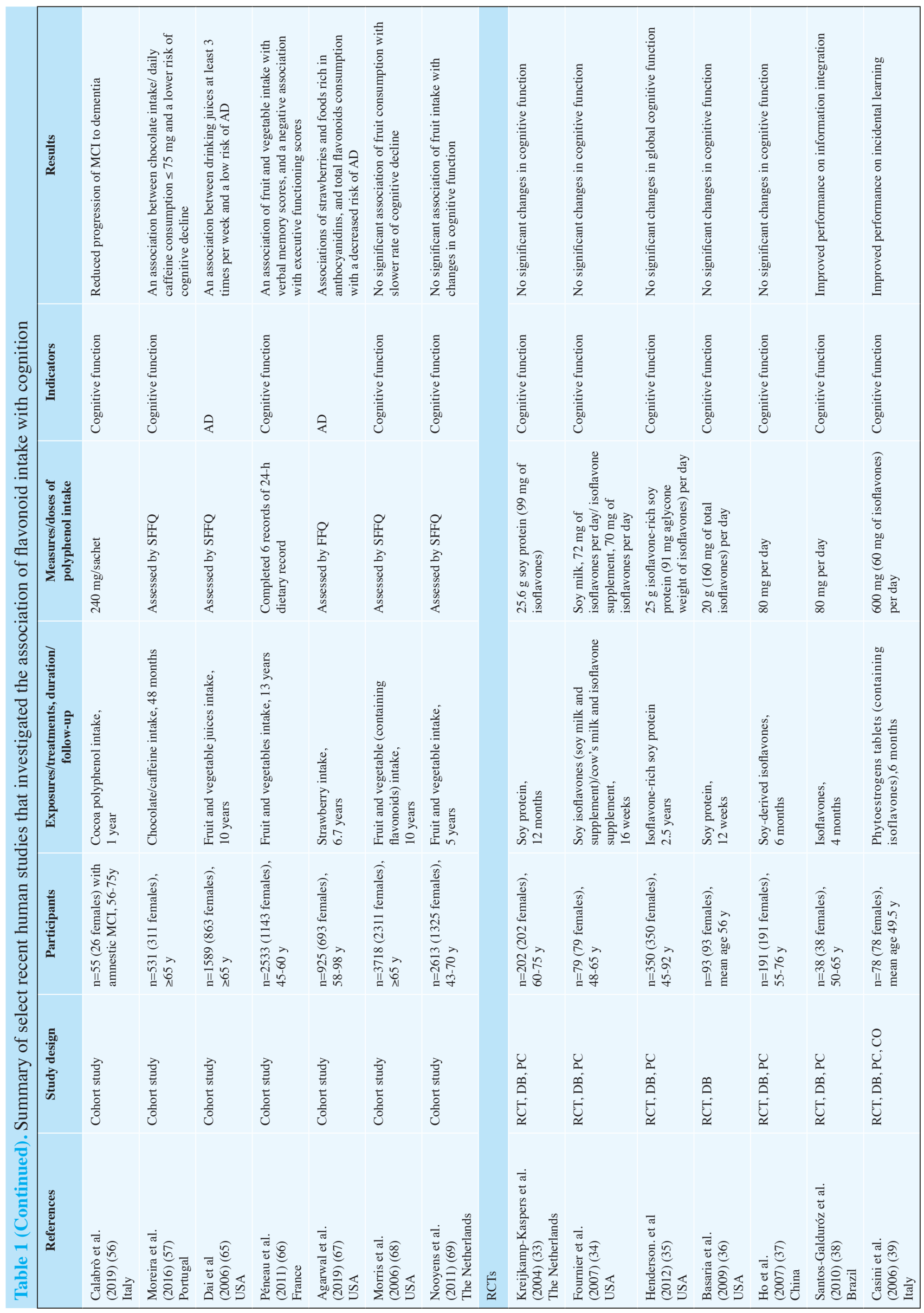




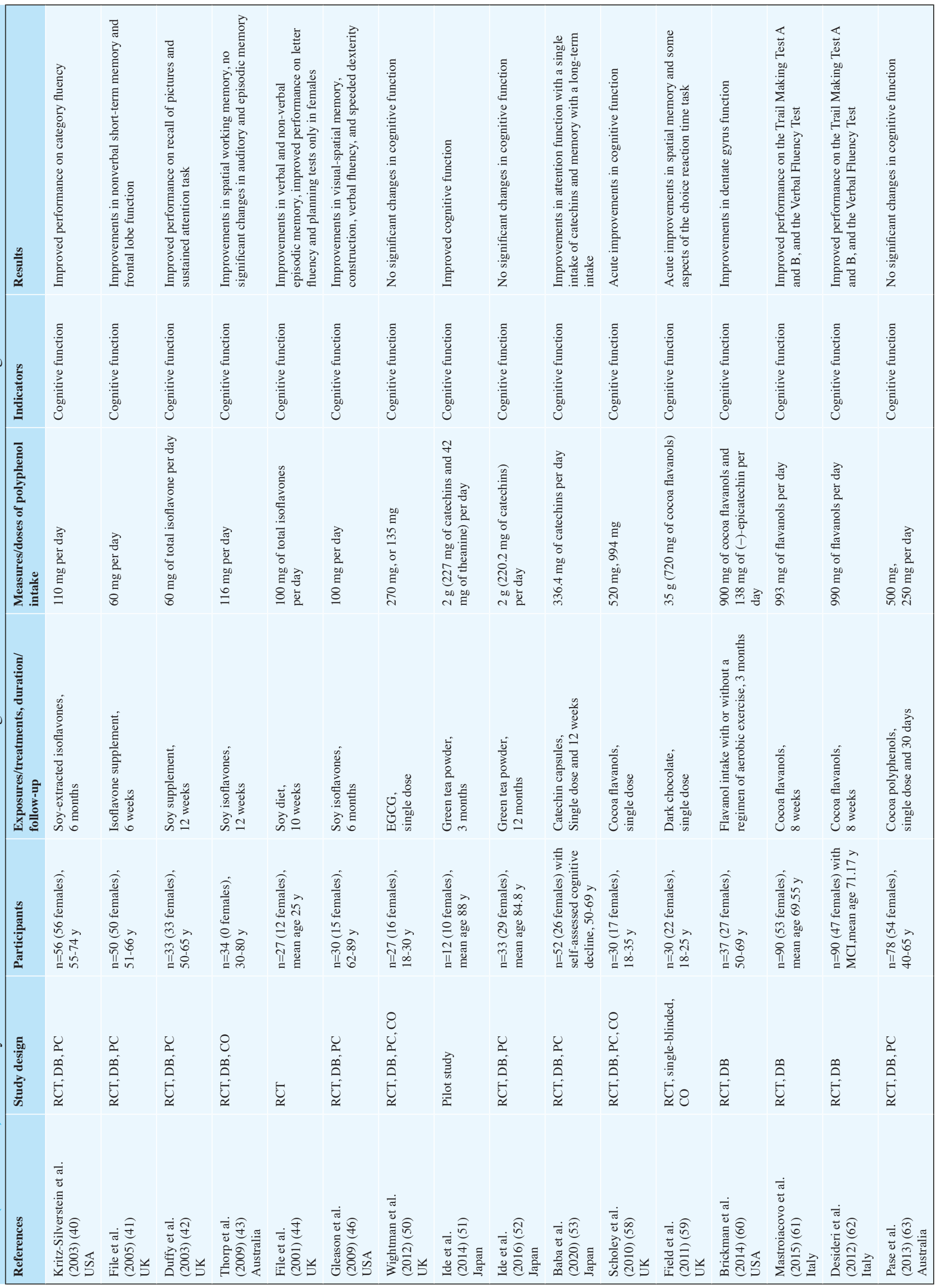




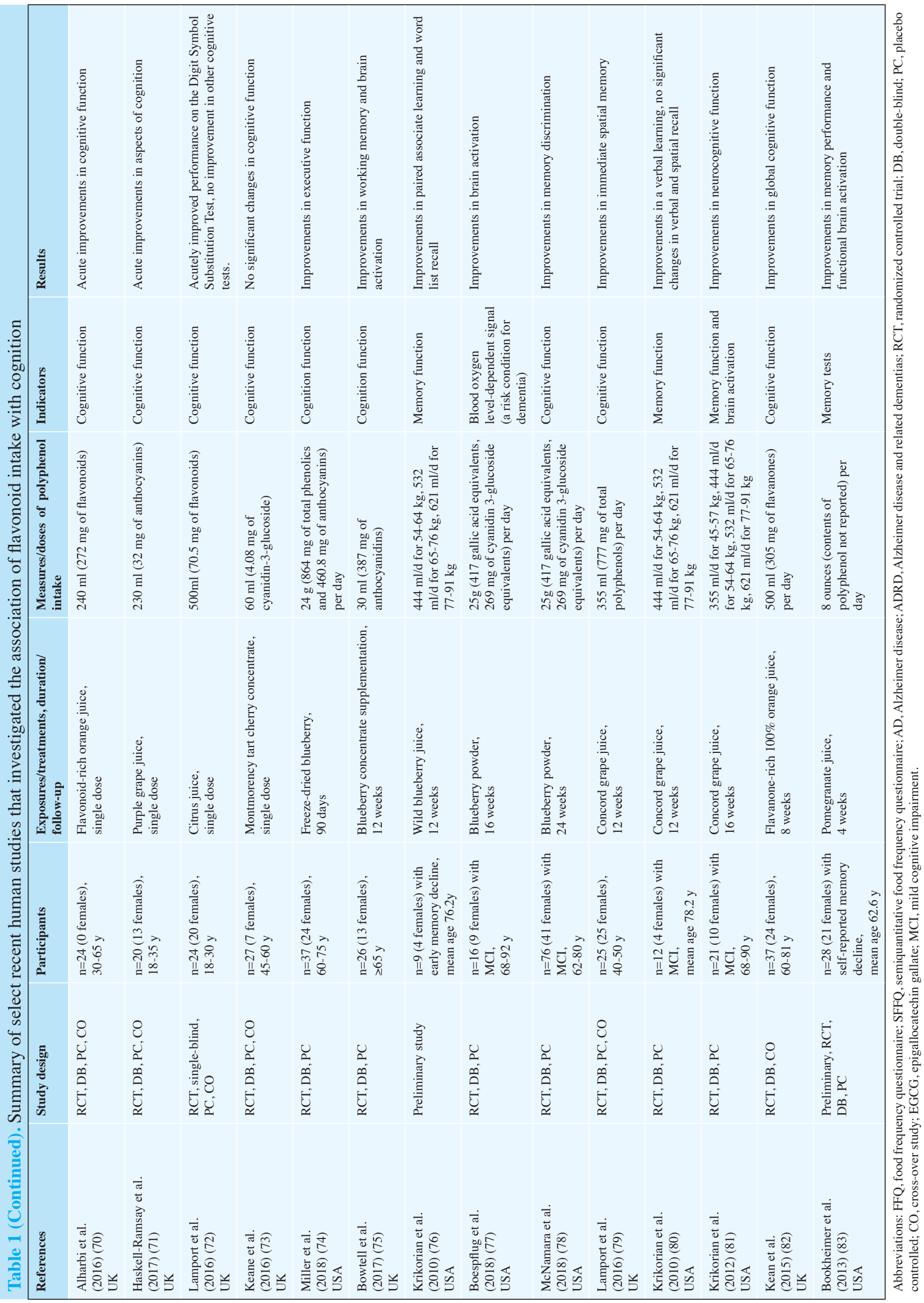


pathophysiological mechanisms with these disorders, it makes sense that polyphenols have the potential neuroprotective effect (5). The suggested biological mechanisms may involve several typical processes: resistance to amyloidosis, inactivation of free radicals, and inhibition of inflammatory response (14, 15), however these mechanisms have not been fully verified and elucidated. Thus, it is helpful to summarize the research on polyphenols in cognitive disorders to provide evidence for future research.

\section{Different polyphenols, cognitive decline, and the risk of dementia}

\section{Flavonoids}

Flavonoids are the biggest class of phenolics that can be further classified into flavonols, flavones, isoflavones, flavanones, anthocyanidins, and flavanols (catechins and proanthocyanidins) according to the type of their ring structure (11). Apart from total or composite flavonoids, representative dietary sources of specific flavonoids have been concerned broadly (Table 1).

In a couple of cross-sectional studies, Nurk et al. (16) found that intake of flavonoid-rich chocolate, wine, and tea is associated with better cognitive performance in a dosedependent manner; however, Butchart et al. (17) did not support the role of flavonoids (from total fruit intake, total vegetable intake, apples, citrus fruits, tea, chocolate, and red wine) in the prevention of cognitive decline. Furthermore, previous population-based prospective cohort studies examined the association between dietary intake of antioxidants (including flavonoids) and long-term risk of dementia (18-22). Contrary to the expectations, most of the results showed that higher intake of foods rich in flavonoids seemed not to modify the risk of dementia or its subtypes. Only Commenges et al. (22) reported an inverse relationship between intake of antioxidant flavonoids and the risk of dementia.

Recently, Shishtar et al. (23) and Devore et al. (24) evaluated the relation between long-term dietary flavonoid intake and cognition in two large cohorts where the intake of flavonoids could be measured repeatedly during the follow-up. The former found that higher dietary intake of total flavonoids (including flavonols, flavones, flavanones, flavan-3-ols, anthocyanins, and flavonoid polymers) is related to a lower risk of AD and Alzheimer's disease and related dementias. The latter one found that greater intake of total flavonoids and berries (high in anthocyanidins) might slow down rates of cognitive decline and delay cognitive aging by as much as 2.5 years in older women. While Letenneut et al. (25) measured the intake of flavonoids only at baseline and showed that higher intake of flavonoids (including quercetin, kaempferol, myricetin, luteolin, and apigenin) is associated with a better cognitive evolution over a 10 -year period.

\section{Flavonoids in soy and soy-derived products}

Isoflavones, one of the better absorbed flavonoids, are specific to soy and soy-based foods, such as soy nuts, tofu, soy milk, and soy butter. In Asian diets, soy isoflavones are more abundant than in Western diets. Isoflavones are also known as phytoestrogens, and their chemical structure is similar to female estrogens. However, it should be noted that there are possible safety issues related to high-dose isoflavone intake, especially from estrogenic and goitrogenic activities (26). Because of such an adverse effect and the lack of consensus regarding the health benefits derived from isoflavone consumption, the American Heart Association does not recommend the use of isoflavone supplements in food or pills (27).

Equol, a metabolite of soy isoflavone, reflects the consumption of isoflavones. Igase et al. (28) conducted a cross-sectional study on the association between equol production status and cognitive function in older adults. In contrast with equol producers, equol non-producers were more susceptible to cognitive decline. Nonetheless, opposite findings deserved attention: two cross-sectional studies in the elderly suggested that higher tofu consumption is associated with lower memory function (29) and worse cognitive performance (30). Furthermore, according to a cohort study, higher tofu consumption in midlife could predict cognitive impairment and brain atrophy in late life among males (31).

Most of the current neuroprotective studies on isoflavones focused on postmenopausal women. These women have lower endogenous estrogen levels after menopause and tend to be at a higher risk of AD (32). A series of randomized controlled trials (RCTs) investigated the effects of soy isoflavones, particularly the estrogen-like actions, on cognition-related aspects. In these studies, doses of total isoflavones varied between 60 and 110 $\mathrm{mg}$ /day; periods of intervention ranged from 12 weeks to 2.5 years. Even if almost half of the studies failed to support a significant role of isoflavones supplementation in improving cognitive function (33-37), others revealed promising results in specific aspects of cognitive function, such as information integration [38], incidental learning (39), category fluency (40), frontal lobe function (41), and recall of pictures and sustained attention task (42).

On the other hand, Thorp et al. (43) paid attention to healthy men. Subjects were randomized to take four capsules (either total containing $116 \mathrm{mg}$ of isoflavone equivalents or placebo) per day for 6 weeks and then they crossed over the alternate treatments for the following 6 weeks. Isoflavone consumption might significantly improve spatial working memory, without being detrimental to the performance on visual-spatial processing. In another RCT by File et al. (44), following 10 weeks of isoflavone administration, young volunteers taking a high soy diet (100 mg/day of total isoflavones) performed better on verbal and non-verbal episodic memory tests, regardless of gender, compared with those taking a low soy diet $(0.5 \mathrm{mg} /$ day of total isoflavones). As for tests of letter fluency and planning, the improved performance from the high soy diet group was found only in females. Hogervorst et al. (45) also stated that higher soy intake is related to better immediate recall memory in younger, but not in older people. While Gleason et al. (46) found mixed evidence of the potential cognitive effects of soy isoflavones. In their study design, older adults were randomized to ingest either $100 \mathrm{mg} /$ day of soy isoflavones or placebo for 6 months. When those consumed isoflavones, improvements in 
the areas of visual-spatial memory, construction, verbal fluency, and speeded dexterity were observed; whereas placebo-treated participants performed better on two tests of executive function.

\section{Flavonoids in tea}

Tea consumption, with a history of about 5000 years in China, is popular around more than half of the world's population. Tea is derived from the Camellia sinensis plant and generally classified into green tea, black tea, and oolong tea according to different fermentation processes (47). With a large quantity of tea polyphenol content and high levels of active enzymes, green tea has been most studied for health benefits. The main components of tea polyphenols are catechins which belong to the flavan-3-ol class of flavonoids, including more than 10 monomers, such as (-)-epigallocatechin-3-gallate (EGCG), (-)-epigallocatechin, (-)-epicatechin-3-gallate, (-)-epicatechin, (-)-catechin-3-gallate, and (-)-gallocatechin-3gallate, usually among which EGCG dominates.

There has been an increasing body of evidence from observational studies that tea consumption is inversely related to the risk of cognitive disorders in the elderly (48 49). Wightman et al. (50) conducted a cross-over study in which adults consumed either placebo or two doses $(135 \mathrm{mg}$ and $270 \mathrm{mg}$ ) of EGCG in counterbalanced order on separate days. Following a 45-min resting absorption period, the intake of EGCG could modulate cerebral blood flow in the frontal cortex but not cognitive performance. Ide et al. assessed the effects of green tea consumption on cognitive function in residents with MCI in their two studies. In a pilot study (51), participants performed better on the Mini-Mental State Examination Japanese (MMSE-J) version than that in baseline when taking 2 $\mathrm{g}$ /day green tea powder (containing $227 \mathrm{mg}$ of catechins) over 3 months. Whereas in the RCT (52), after 12-month consumption, changes of MMSE-J score in the green tea powder (containing $220.2 \mathrm{mg}$ of catechins, per day) group and placebo group did not differ significantly. Baba et al. (53) aimed to clarify the role of green tea catechins alone. Subjects with self-assessed cognitive decline took either three catechin capsules (containing $336.4 \mathrm{mg}$ of catechins, caffeine-free) or placebo per day for 12 weeks. An improvement in attention function after a single intake of catechins and beneficial effects of long-term intake on working memory were found.

\section{Flavonoids in cocoa}

Cocoa, from the dried and fermented seeds of Theobroma cacao, originates in the tropical regions of South America. It contains high levels of flavonoids, in particular the flavanols subclass, and is most often consumed in the form of chocolate. The flavanol contents in cocoa products and chocolate differ greatly depending on the cocoa bean variety and origin, agricultural and processing practices, which may be responsible for some mixed outcomes observed in research on the effects of cocoa flavanols on neurocognitive function (54).

A cross-sectional study indicated that consumption of chocolate at least once a week is associated with improved global composite memory, and visuospatial memory and organization (55). Calabrò et al. (56) carried out a retrospective study in which cocoa flavonoids reduced a worsening in cognition assessed by MMSE in patients with MCI. In a prospective cohort study, cocoa/chocolate consumption might slow the cognitive decline in elderly people who consumed less than $75 \mathrm{mg}$ /day of caffeine (57).

Scholey et al. (58) and Field et al. (59) found acute improvements in cognitive performance after consumption of cocoa flavanols. Brickman et al. (60) also revealed that higher cocoa flavanol intake ( $900 \mathrm{mg} /$ day) for 3 months enhanced dentate gyrus function, considered to be related to age-related memory decline, and thereby improved the cognition in older adults. Mastroiacovo et al. (61) and Desideri et al. (62) designed two similar RCTs in elderly adults and those with MCI, respectively. Subjects were instructed to take a drink containing approximately $990 \mathrm{mg}, 520 \mathrm{mg}$, or $45 \mathrm{mg}$ of cocoa flavanols once daily over 8 weeks. The performance on the Trail Making Test A and B as well as the verbal fluency test was significantly better in those with the highest flavanol intake, for whichever population. Pase et al. (63) examined the acute and sub-chronic neuroprotective effects of cocoa polyphenols. Participants were individually assigned to receive a daily dark chocolate drink mix containing $500 \mathrm{mg}, 250 \mathrm{mg}$ of polyphenols, or placebo for 30 days. However, cognitive aspects were unchanged by any dose of administration at all-time points.

\section{Flavonoids in fruits}

Fruits and fruit juices are excellent sources of flavonoids. Anthocyanins are mainly found in red and blue fruits, in particular berries, such as blueberries, raspberries, red grapes, and cherries (13). Flavanones are present in high concentrations in citrus fruit, involving naringenin from grapefruit, hesperetin from oranges, and eriodictyol from lemons (64). Additionally, $100 \%$ fruit juice consumption is recommended compared with nutrient-poor sugar-sweetened beverages (5).

Epidemiological data suggested a link between fruit (juice) consumption and age-related cognitive decline. In a cohort study of older dementia-free Japanese Americans, the consumption of fruit/vegetable juice, containing a high concentration of polyphenols, is inversely related to $\mathrm{AD}$ risk. And the effect was independent of vitamin C, E, $\beta$-carotene, and tea consumption, indicating that polyphenols in fruit/ vegetable juice might be responsible (65). Péneau et al. (66) observed the beneficial effect of consumption of fruits and vegetables or fruits alone on the performance on verbal memory after a 13-year follow-up. Agarwal et al. (67) found that higher intake of strawberry rich in anthocyanidins is associated with a decreased risk of $\mathrm{AD}$ during the mean 6.7 years of followup. Nevertheless, Morris et al. (68) and Nooyens et al. (69) reported that higher vegetable but not fruit consumption might be associated with less cognitive decline in the cohorts.

Some RCTs addressed the acute effects of polyphenols from fruits. Alharbi et al. (70) stated that middle-aged males taking a $240 \mathrm{ml}$ of orange juice (containing a total of 272 $\mathrm{mg}$ of flavonoids) performed better significantly on the tests 
Table 2. Summary of RCTs that investigated the association of curcumin intake with cognition

\begin{tabular}{|c|c|c|c|c|c|c|}
\hline References & Study design & Participants & $\begin{array}{l}\text { Exposure/ } \\
\text { treatment, duration/ } \\
\text { follow-up }\end{array}$ & $\begin{array}{l}\text { Dose of polyphenol } \\
\text { intake }\end{array}$ & Indicators & Results \\
\hline $\begin{array}{l}\text { DiSilvestro et al. } \\
\text { (2012) (86) } \\
\text { USA }\end{array}$ & $\mathrm{RCT}, \mathrm{PC}$ & $\begin{array}{l}\mathrm{n}=38(34 \\
\text { females }) \\
40-60 \mathrm{y}\end{array}$ & $\begin{array}{l}\text { Lapidated curcumin, } \\
4 \text { weeks }\end{array}$ & $\begin{array}{l}400 \text { mg Longvida }{ }^{\circledR} \\
\text { Optimized Curcumin } \\
\text { ( } 80 \mathrm{mg} \text { of curcumin) } \\
\text { per day }\end{array}$ & $\begin{array}{l}\text { Health promoting } \\
\text { effects }\end{array}$ & $\begin{array}{l}\text { A decrease of plasma amy- } \\
\text { loid } \beta \text {-protein concentrations }\end{array}$ \\
\hline $\begin{array}{l}\text { Cox et al. } \\
(2015)(87) \\
\text { Australia }\end{array}$ & $\mathrm{RCT}, \mathrm{DB}, \mathrm{PC}$ & $\begin{array}{l}n=60(38 \\
\text { females), } \\
60-85 y\end{array}$ & $\begin{array}{l}\text { Curcumin } \\
\text { formulation, single } \\
\text { dose and } 4 \text { weeks }\end{array}$ & $\begin{array}{l}400 \text { mg Longvida }{ }^{\circledR} \\
\text { Optimized Curcumin } \\
\text { (80 mg of curcumin) }\end{array}$ & Cognitive function & $\begin{array}{l}\text { Improved performance } \\
\text { on sustained attention and } \\
\text { working memory tasks after } \\
1 \text { hour and working memory } \\
\text { following } 4 \text { weeks }\end{array}$ \\
\hline $\begin{array}{l}\text { Lee et al. } \\
\text { (2014) (88)) } \\
\text { Chinese Taiwan }\end{array}$ & RCT, DB, PC & $\begin{array}{l}\mathrm{n}=48(25 \\
\text { females), } \\
\geq 60 \mathrm{y}\end{array}$ & $\begin{array}{l}\text { Turmeric, } \\
\text { single dose }\end{array}$ & $\begin{array}{l}1 \mathrm{~g} \text { (contents of } \\
\text { curcumin not reported) }\end{array}$ & Working memory & $\begin{array}{l}\text { Improvements in working } \\
\text { memory }\end{array}$ \\
\hline
\end{tabular}

Abbreviations: RCT, randomized controlled trial; DB, double-blind; PC, placebo controlled.

of objective and subjective cognition over the course of 6 hours. Haskell-Ramsay et al. (71) found that $230 \mathrm{ml}$ of grape juice (consisting of Welch's ${ }^{\mathrm{TM}}$ purple grape juice plus Schweppes ${ }^{\mathrm{TM}}$ blackcurrant favour cordial, containing $32 \mathrm{mg}$ of anthocyanins) intake enhanced aspects of cognition in young adults after a 20-min absorption period. Lamport et al. (72) observed a role of $500 \mathrm{ml}$ of citrus juice (containing $70.5 \mathrm{mg}$ of flavonoids) intake in increasing cerebral blood flow and improving the performance in the digit symbol substitution test but no other behavioral cognitive tests among young adults 2 hours following the consumption. Likewise, Keane et al. (73) showed that cherry concentrate consumption could modulate some variables of vascular function immediately rather than cognition.

Clinical evidence reporting similar chronic benefits also existed. Numerous investigations showed that blueberry products appeared to contribute to brain health in older adults, such as executive function (74), working memory and brain activation (75), paired associate learning and word recall (76), brain activation (77), and memory discrimination (78). Concord grape juice (by Welch Foods, Inc) supplementation was reported to improve spatial memory and driving performance in middle-aged working mothers (79) and memory function in older adults with MCI $(80,81)$. Kean et al. (82) found that 8 -week, daily $500 \mathrm{ml}$ of $100 \%$ orange juice (containing $305 \mathrm{mg}$ of flavanones) consumption was beneficial for global cognitive function. A daily 8-ounce pomegranate juice (the commercial Pom Wonderful product, contents of polyphenol not reported) consumption for 4 weeks was also found to benefit memory performance, perhaps affected through increased taskspecific cerebral blood flow, and functional brain activation among older persons with self-reported memory decline (83). Furthermore, Nilsson et al. (84) focused on a mixed berry juice that consisted of blueberries, blackcurrant, elderberry, lingonberries, strawberry, and tomatoes, with $795 \mathrm{mg}$ daily amounts of total polyphenols. Subjects performed better on the working memory test after the 5 weeks of intervention.

\section{Curcumin}

Curcumin is a yellowish pigment and a well-known nonflavonoid polyphenol, belonging to the group of phenolic acids. Curcumin is the major bioactive component in Curcuma longa that has a long history of application as a dye, a spice, and as an anti-inflammatory agent in traditional medicines in China and India (85). Notably, because curcumin itself displays low solubility in water and a poor pharmacokinetic profile, novel curcumin formulations that make up for these defects and are available commercially are in common use in human trials (Table 2).

DiSilvestro et al. (86) investigated various actions of a low dose of curcumin on wellness-related measures. This study showed a decrease of plasma amyloid $\beta$-protein concentrations after a daily supplement of lipidated curcumin (Longvida ${ }^{\circledR}$ Optimized Curcumin from Curcuma Longa root, containing $80 \mathrm{mg}$ of curcumin) for 4 weeks, which was associated with the mechanism by which curcumin might influence brain aging and the development of AD. Moreover, with prolonging the duration of intervention, this decrease could become larger, suggesting curcumin might produce potential health promotion on cognition. An RCT by Cox et al. (87) was the first study to explore the roles of curcumin on cognition and reported significant acute (one hour after a single dose) effect of solid lipid curcumin formulation (Longvida ${ }^{\circledR}$ Optimized Curcumin, containing approximately $80 \mathrm{mg}$ of curcumin) on enhanced performance on sustained attention and working memory tasks. After a chronic daily treatment (4 weeks), working memory and mood were also significantly improved. This study provided clues that curcumin even at a low dose had the potential to improve cognitive function. Lee et al. (88) focused on a role 
of turmeric on post-prandial working memory in elderly adults with pre-diabetes but dementia-free. It showed that ingestion of turmeric ( $1 \mathrm{~g}$, contents of curcumin not reported) increased working memory independent of amyloid precursor protein, the biomarker of AD, 6 hours after supplementation. A recent longterm (18 months) RCT by Small et al. (89) displayed that taking Theracurmin ${ }^{\circledR}$ twice daily (i.e., $180 \mathrm{mg} /$ day of curcumin) might make for significant memory and attention benefits, which was associated with decreases in amyloid and tau accumulation in brain regions. Rainey-Smith et al. (90) carried out a 12-month RCT where community-dwelling adults with good health received either $1500 \mathrm{mg} /$ day Biocurcumax ${ }^{\mathrm{TM}}$ (containing 88\% curcuminoids and $7 \%$ volatile oil) or placebo. No significant difference in cognitive performance after supplementation was observed except for a significant time $\times$ treatment group interaction on the Montreal Cognitive Assessment (MoCA). Nevertheless, this association was owing to a decline in MoCA scores of the placebo group at 6 months that was not observed in the curcumin treatment group. And at 12 months, there was also nonsignificant difference in the MoCA scores between the two groups.

\section{Resveratrol}

Resveratrol is one of the most intensively studied among the stilbene compounds with mother-nucleus of distyrenes. It was first isolated from white hellebore (Veratrum grandiflorum O. Loes) roots in 1940 and later isolated from Polygonum cuspidatum roots in 1963. To date, this natural polyphenol resveratrol has been detected in more than 70 plant species (91). However, dietary sources of resveratrol are relatively limited and are mainly red wines, peanuts, pistachios, berries, and grapes (92). The compound is determined in two isomers: cis-isomer and trans-isomer, of which trans-resveratrol is concerned by most research due to its greater chemical stability and wider biological activities (93).

Both Kennedy et al. (94) and Wightman et al. (95) focused on the acute effect of resveratrol with regard to cerebral blood flow and cognitive performance in young adults. The former found that subjects' cerebral blood flow increased after a 45 -min resting absorption of resveratrol $(250 \mathrm{mg}$ or $500 \mathrm{mg}$ ), but with little change in cognitive function. Given the hypothesis that piperine could alter resveratrol pharmacokinetics and enhance its bioavailability (96), the latter further ascertained the combined effect of resveratrol and piperine. Similar to the results above, only cerebral blood flow instead of cognitive performance was improved after a 40-min rest/absorption period, despite with a co-supplementation of $250 \mathrm{mg}$ of resveratrol with $20 \mathrm{mg}$ of piperine. In addition, the findings indicated that piperine seemed not to induce an overall increase in the bioavailability of resveratrol. Wong et al. (97) also studied the acute (75 min after a single dose) effect of different resveratrol concentrations in patients with type 2 diabetes but found no significant change in overall cognitive performance. While patients performed better on the multitasking test battery that assessed visual scanning and attention, working memory, and executive function, which might be correlated with the enhanced neurovascular coupling capacity, after taking $75 \mathrm{mg}$ or $300 \mathrm{mg}$ of resveratrol.

On the other hand, Wightman et al. (98) conducted an RCT to explore the chronic effect of 28-day supplementation of $500 \mathrm{mg}$ of resveratrol. But it was little beneficial for aspects of cognitive function except accuracy of the 3-Back task in young people, even if on day 1 there was the effect on more accurate but slower serial subtraction task performance. Moran et al. (99) investigated the impact of a daily multi-ingredient supplementation (containing $150 \mathrm{mg}$ of resveratrol) for 6 months. But a limited beneficial impact on overall cognitive function and composite domains (including executive function, memory, attention, sensorimotor speed, motor imagery accuracy, and subjective awareness of cognitive failures) was captured, either. Whereas Anton et al. (100) reported that compared with $300 \mathrm{mg} /$ day of resveratrol and placebo, 1000 $\mathrm{mg}$ /day of supplementary resveratrol for 90 days improved psychomotor speed but in the absence of other domains of cognitive function in older overweight adults. Moreover, Witte et al. (101) and Huhn et al. (102) assessed the role of resveratrol in the elderly who were overweight and who were with a wide body-mass index range, respectively. In both two studies, subjects were randomized into either $200 \mathrm{mg} /$ day of resveratrol or placebo for 26 weeks. Contradictory results were obtained: the first study found significant effects of resveratrol on retention of memory and an increase in functional connectivity of hippocampus with frontal, parietal, and occipital areas, which is a key region involved in memory function. Furthermore, resveratrol could benefit glucose metabolism that might further mediate neuronal function and cognitive performance. The second study failed to find any improvement in verbal memory and changes in hippocampus volume, microstructure, and functional connectivity. Furthermore, another 26-week trial investigated whether the beneficial impacts of resveratrol could extend to patients with MCI (103), in which resveratrol supplementation at a dose of $200 \mathrm{mg} /$ day could preserve hippocampus volume and improve hippocampal resting-state functional connectivity. Whereas no significant influence of resveratrol on memory performance or microstructure of hippocampal neurogenesis was detected. In post-menopausal women, $75 \mathrm{mg}$ of resveratrol ingested twice daily over 14 weeks resulted in better cognitive performance, which might be at least partially driven through improvement in cerebrovascular responsiveness to cognitive stimuli (104). Also, in such a population, other researchers hypothesized that by ameliorating circulatory function and regional blood flow in the brain, resveratrol could enhance mood and cognition (105) (Table 3).

\section{Other polyphenols}

Kreijkamp-Kaspers et al. (106) performed a cross-sectional study to explore the possible influence of isoflavone and lignan intake on cognitive function in women. As was reported, high lignan intake was associated with better processing capacity RCT, DB, PC and speed, and executive function. Nevertheless, no significant association between taking isoflavones and cognitive function was observed. These findings were replicated in another cross-sectional study in postmenopausal 
Table 3. Summary of RCTs addressing the association of resveratrol intake with cognition

\begin{tabular}{|c|c|c|c|c|c|c|}
\hline References & Study design & Participants & $\begin{array}{l}\text { Exposure/treatment, } \\
\text { duration/follow-up }\end{array}$ & $\begin{array}{l}\text { Dose of polyphenol } \\
\text { intake }\end{array}$ & Indicators & Results \\
\hline $\begin{array}{l}\text { Kennedy et al. } \\
(2010)(94) \\
\text { UK }\end{array}$ & $\begin{array}{l}\mathrm{RCT}, \mathrm{DB}, \mathrm{PC}, \\
\mathrm{CO}\end{array}$ & $\begin{array}{l}\mathrm{n}=22(18 \text { females }), \\
18-25 \mathrm{y}\end{array}$ & $\begin{array}{l}\text { Resveratrol, } \\
\text { single dose }\end{array}$ & 250 and $500 \mathrm{mg}$ & $\begin{array}{l}\text { Cognitive } \\
\text { function }\end{array}$ & $\begin{array}{l}\text { No significant changes in } \\
\text { cognitive function }\end{array}$ \\
\hline $\begin{array}{l}\text { Wightman et al. } \\
(2014)(95) \\
\text { UK }\end{array}$ & $\begin{array}{l}\mathrm{RCT}, \mathrm{DB}, \mathrm{PC}, \\
\mathrm{CO}\end{array}$ & $\begin{array}{l}\mathrm{n}=23 \text { (19 females), } \\
19-34 \text { y }\end{array}$ & $\begin{array}{l}\text { Resveratrol with or } \\
\text { without piperine, single } \\
\text { dose }\end{array}$ & $\begin{array}{l}250 \mathrm{mg} \text { (with or } \\
\text { without } 20 \mathrm{mg} \text { of } \\
\text { piperine) }\end{array}$ & $\begin{array}{l}\text { Cognitive } \\
\text { function }\end{array}$ & $\begin{array}{l}\text { No significant changes in } \\
\text { cognitive function }\end{array}$ \\
\hline $\begin{array}{l}\text { Wightman et al. } \\
(2015 \text { (98) } \\
\text { UK }\end{array}$ & RCT, DB, PC & $\begin{array}{l}\mathrm{n}=60 \text { (51 females }) \\
18-30 \mathrm{y}\end{array}$ & $\begin{array}{l}\text { Resveratrol, } \\
28 \text { days }\end{array}$ & $500 \mathrm{mg}$ per day & $\begin{array}{l}\text { Cognitive } \\
\text { function }\end{array}$ & $\begin{array}{l}\text { Improved perfor mance on } \\
\text { accuracy of the 3-Back task } \\
\text { but not other aspects of } \\
\text { cognitive function }\end{array}$ \\
\hline $\begin{array}{l}\text { Anton et al. } \\
(2018)(100) \\
\text { USA }\end{array}$ & $\begin{array}{l}\text { RCT (Phase IIa), } \\
\text { DB, PC }\end{array}$ & $\begin{array}{l}\mathrm{n}=32(16 \text { females }) \\
65-93 \text { y }\end{array}$ & $\begin{array}{l}\text { Resveratrol, } \\
90 \text { days }\end{array}$ & $\begin{array}{l}\text { High-dose (1000 } \\
\mathrm{mg} / \mathrm{d})\end{array}$ & $\begin{array}{l}\text { Cognitive } \\
\text { function }\end{array}$ & $\begin{array}{l}\text { Improvements in } \\
\text { psychomotor speed, no } \\
\text { significant changes in } \\
\text { other domains of cognitive } \\
\text { function }\end{array}$ \\
\hline $\begin{array}{l}\text { Witte et al. } \\
\text { (2014) (101) } \\
\text { Germany }\end{array}$ & RCT, DB, PC & $\begin{array}{l}\mathrm{n}=46(18 \text { females }) \\
50-75 \mathrm{y}\end{array}$ & $\begin{array}{l}\text { Resveratrol, } \\
26 \text { weeks }\end{array}$ & $200 \mathrm{mg}$ per day & $\begin{array}{l}\text { Memory } \\
\text { performance }\end{array}$ & $\begin{array}{l}\text { Improvements in memory } \\
\text { performance and functional } \\
\text { connectivity of hippocampus }\end{array}$ \\
\hline $\begin{array}{l}\text { Huhn et al. } \\
\text { (2018) (102) } \\
\text { Germany }\end{array}$ & RCT, DB, PC & $\begin{array}{l}\mathrm{n}=53(28 \text { females }), \\
60-79 y\end{array}$ & $\begin{array}{l}\text { Resveratrol, } \\
26 \text { weeks }\end{array}$ & 200 mg per day & $\begin{array}{l}\text { Verbal memo- } \\
\text { ry perfor- } \\
\text { mance }\end{array}$ & $\begin{array}{l}\text { No significant changes in } \\
\text { verbal memory performance }\end{array}$ \\
\hline $\begin{array}{l}\text { Evans et al. } \\
\text { (2016) (105) } \\
\text { Australia }\end{array}$ & RCT, DB, PC & $\begin{array}{l}\mathrm{n}=80(80 \text { females }) \\
45-85 \mathrm{y}\end{array}$ & $\begin{array}{l}\text { Resveratrol, } \\
14 \text { weeks }\end{array}$ & $150 \mathrm{mg}$ per day & $\begin{array}{l}\text { Cognitive } \\
\text { function }\end{array}$ & $\begin{array}{l}\text { Improvements in cognitive } \\
\text { function }\end{array}$ \\
\hline
\end{tabular}

Abbreviations: RCT, randomized controlled trial; DB, double-blind; PC, placebo controlled; CO, cross-over study; MCI, mild cognitive impairment.

women in the same locality (107). Likewise, Nooyens et al. (108) follow antioxidants (including flavonoids and lignans) with interest and found that higher lignan intake is associated with less decline in global cognitive function, memory, and speed processing while higher flavonoid intake is also related to cognitive flexibility.

Rabassa et al. (109) carried out a cohort study with 3 years of follow-up in an older population. High concentration of total urinary polyphenols, a nutritional biomarker of dietary polyphenols, was reported to be associated with a lower risk of cognitive decline. However, no significant effect of total dietary polyphenols on cognition was observed. Another large prospective study with a 13-year follow-up identified the associations of total or class-specific polyphenol intake with cognitive function (110). According to this study, there was a significant association of higher total polyphenol intake with better performance on verbal memory rather than executive function. More specifically, intake of total flavonoids, catechins, theaflavins, flavonols, and hydroxybenzoic acids was positively associated with language and verbal memory. Unexpectedly, some specific polyphenols, such as catechins, proanthocyanidins, and flavonols, might have an adverse effect on executive function. Lefèvre-Arbogast et al. (111) examined the long-term (12 years) association between the intake of 26 polyphenol subclasses and dementia risk in a 3-city cohort. This study identified that a pattern of polyphenol intake combining several flavonoids (including dihydroflavonols, anthocyanins, isoflavonoids, and flavanones), stilbenes (including resveratrol), lignans, and other subclasses is associated with a lower risk of all-cause dementia and AD. Furthermore, Lee et al. (112) concerned for patients with mild decline in cognition who were at a high risk for dementia. Participants were randomized 
Table 4. Summary of select recent human studies that investigated the association of other polyphenol intake with cognition

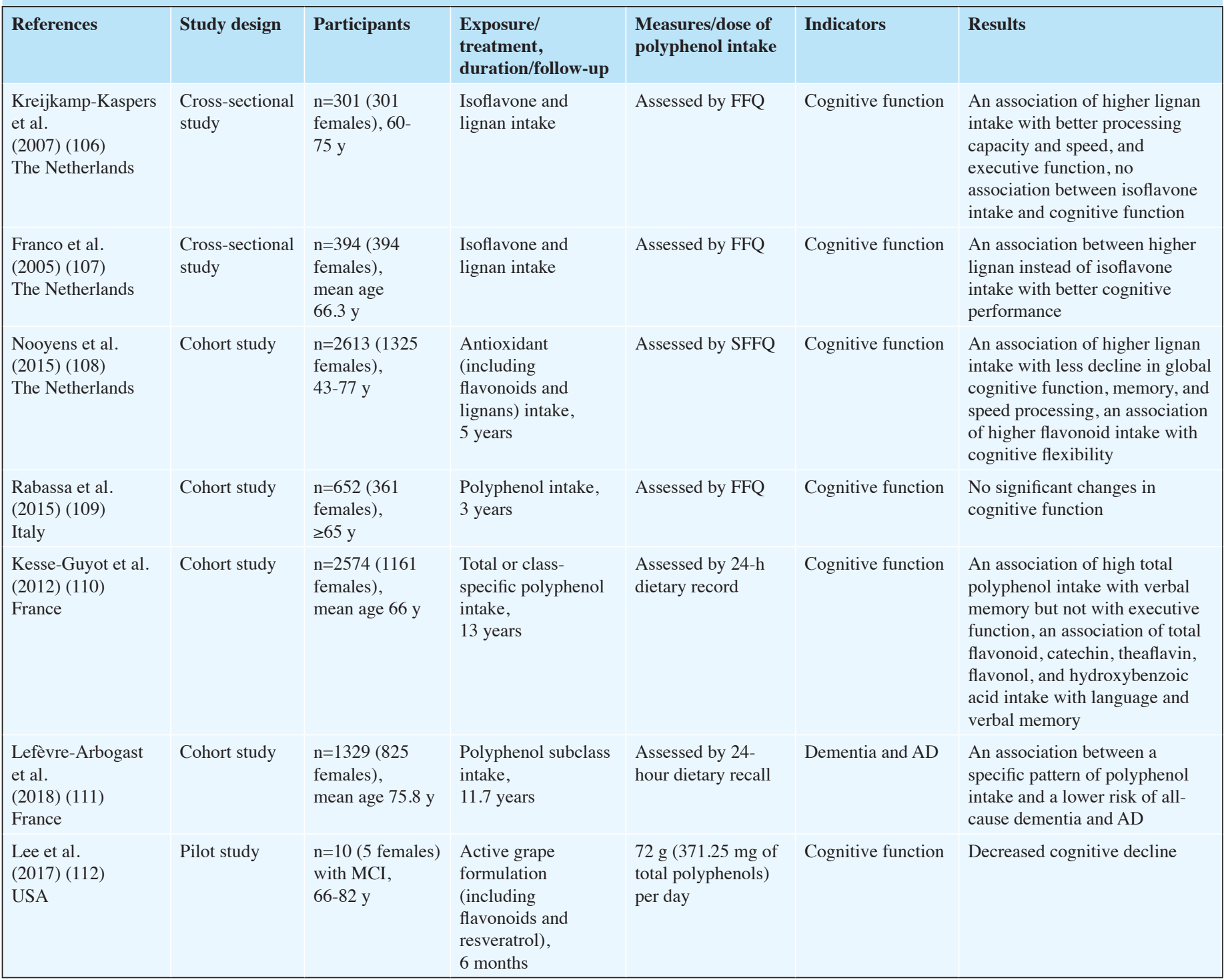

Abbreviations: SFFQ, semiquantitative food frequency questionnaire; FFQ, food frequency questionnaire; AD, Alzheimer disease; MCI, mild cognitive impairment.

to take either $72 \mathrm{~g} /$ day active grape formulation (in which flavonoids and resveratrol abundantly exist) or placebo over 6 months. There were declines in region of the brain having metabolism in relation to aging and development of early stages of $\mathrm{AD}$ in the placebo group, yet grape consumption could protect against those declines, which in turn contribute to the improvement in attention and working memory performance (Table 4).

\section{Discussion}

Our search retrieved published 28 epidemiological studies and 55 clinical trials exploring the roles of polyphenols in cognitive outcomes. Polyphenol intake appears safe and welltolerated with no excess side effects within the ranges of dose used and the duration of studies. Overall, there has been promising evidence that polyphenol-rich foods including soy, tea, cocoa, fruits, and related products, as well as curcumin and resveratrol, have the potential to improve cognition and increase resistance to age-related cognitive decline, at least among individuals without dementia or $\mathrm{AD}$.

Despite the findings from some studies where the observed indicators are the incidence of dementia/AD or gross cognition are conflicting, the more inspiring results come from studies that have applied multiple measures on the specific cognitive domains. Acute benefits of certain polyphenols after a single dose are likely, in particular on attention function and working memory; longer-term intake is necessary to achieve observable effects. These polyphenols may have the most notable effect on memory and executive function. This is in accordance with possible mechanisms underlying the neuroprotective effects of polyphenols, namely by improvement of cerebral blood flow and connectivity of hippocampus as well as reduction of oxidative stress and neuroinflammation function (113, 114 ), which are specifically related to the cognitive process in memory and frontal executive function $(115,116)$. In addition, these benefits may be also relevant for younger adults. The ongoing study on polyphenol consumption in older adults at risk for dementia/AD is significant, while it is possible that the 
window of opportunity to ameliorate the age-related cognitive deterioration by nutritious diet emerges early in the life course (117).

In fact, the bioavailability of oral natural polyphenols is low in humans, among which the resveratrol bioavailability is even less than $1 \%$, regardless of dose escalation and repeated dose administration (118). The states of polyphenols and matrix in which polyphenols present influence their bioavailability. Thus, it is plausible that the combination of polyphenols with other diets may exert synergistic effects on cognitive wellness. For instance, the bioavailability of tea EGCG is increased when co-administrated with caffeine (119). After an administration accompanied by piperine, the bioavailability of curcumin or resveratrol is strongly elevated (96). One previous literature has also suggested that combing specific polyphenols could be more relevant for brain fitness than a single supplement of polyphenol subclasses (111). Thus, identification of synergism between polyphenols and other nutritions becomes an area of interest. On the other hand, diverse formulations have been produced to enhance the oral bioavailability of polyphenols. In the formulation Longevinex ${ }^{\circledR}$, resveratrol is supplemented with $5 \%$ quercetin and $5 \%$ rice bran phytate and these ingredients are micronized to increase the bioavailability (8). Curcumin formulations (Longvida ${ }^{\circledR}$ Optimized Curcumin, Biocurcumax $^{\mathrm{TM}}$, and Thercurcumin ${ }^{\circledR}$ ) have been also shown to yield 27- to 185-fold bioavailability compared with conventional curcumin (120). When dietary supplementation of polyphenols is regarded as a novel therapeutic approach, its poor bioavailability needs to be overcome.

The studies in this review are concentrated in nondementia human subjects, resulting in a modest number of articles and inconsistent results exist. Methodological aspects must be considered carefully. With regard to the majority of observational studies, assessment of polyphenol intake levels tends to be not accurate enough as a result of under- or overestimation of food consumption from self-reports and differences in the assessment of nutrient composition with inconsistent food composition tables. As an example, a single 24-hour dietary recall may not represent usual food selection (19). Moreover, the measurements of diet at one point cannot reflect long-term intake owing to possible changes in dietary practices over the years. There remain discrepancies regarding the cognitive performance measured and the tasks used, and there is even quite a little confusion on the terms applied for the same test, which makes across-study comparisons difficult. Besides, some tests of global cognition used to screen cognitive deficits or dementia, such as the MMSE, appear not sensitive enough to detect subtle domains. It could be more powerful to utilize demanding neuropsychological tests covering a wider range of functions. If conditions permit, the use of functional magnetic resonance imaging can better support findings from cognitive screenings. On the other hand, the durations of intervention range from 4 weeks to 2.5 years in non-acute RCTs, but with no obvious association between intervention duration and its efficacy, and it remains unclear how long it will take to induce significant changes in cognition after a related supplementation. In addition, many factors to which cognitive function is sensitive should be taken into account, such as mood, sleep, physical activities, other illnesses, and genetic factors $(5,117)$. Finally, RCTs can provide stronger evidence on the causal association of polyphenol intake with cognitive function; nevertheless, the sample sizes are relatively small, with fewer than 100 participants in the majority of studies, and the effect of short-term supplementation in clinical studies may not be comparable with long-term dietary intake (20). Therefore, future investigations with a larger sample of subjects (particularly in pre-clinical or MCI stage), longer intervention periods, and longer follow-up after the end of supplement use should determine whether those benefits can be validated and transferred to humans.

\section{Conclusion}

In the absence of curative treatment, nutrients from health diet are important modifiable factors for cognitive aging and dementia. Polyphenols, particularly flavonoids, curcumin, and resveratrol, have pleiotropic biological activities capable of being ideal candidates to preserve or improve cognitive performance that precedes the onset of dementia/AD. Certainly, discrepancies in study design partly bring about inconsistent findings on the same component. Noteworthy, it is essential to identify the effective dose and duration of supplementation, enhance the bioavailability of substances, and establish standardized preparation, to ensure polyphenol levels sufficient for the protective action. Furthermore, the possibility of interactions with other bioactives present in foods or that can be administered as supplements (e.g., fiber, terpenoids, and alkaloids) deserves consideration. Even if human polyphenol research on cognitive function is at an early stage and much work needs to be done, the observed associations are promising and call for future investigation.

Ethical standard: This review paper is in accordance with the ethical standards of the institutional and/or national research committee and with the 1964 Helsinki Declaration and its later amendments or comparable ethical standards.

Consent for publication: All co-authors have agreed to the submission and publication of this manuscript.

Conflict of interest: The authors declare no conflicts of interest.

Funding: W.X. received grants from the Swedish Research Council (No. 2017-00981) the National Natural Science Foundation of China (No. 81771519), the Konung Gustaf V:s och Drottning Victorias Frimurare Foundation (No. 2016-2020), Demensfonden, Strokefonden, Cornells Stiftelse and Alzheimerfonden (2018-2019). This project is part of CoSTREAM (www.costream.eu) and received funding from the European Union's Horizon 2020 research and innovation program under grant agreement No 667375

Authors' contributions: W.Y., and K.C. performed the literature review and wrote the first draft of the paper; X.L., J.Z., Z.Z., R.S., X.Q., and W.X. revised the draft of the manuscript and provided critical comments; X.Q., and W.X. had primary responsibility for final content. All authors read and approved the final manuscript.

Open Access: This article is distributed under the terms of the Creative Commons Attribution 4.0 International License (http://creativecommons.org/licenses/by/4.0/), which permits use, duplication, adaptation, distribution and reproduction in any medium or format, as long as you give appropriate credit to the original author(s) and the source, provide a link to the Creative Commons license and indicate if changes were made.

\section{References}

1. EB Larson, K Yaffe, KM Langa. New insights into the dementia epidemic. N Engl J Med 2013;369(24):2275-2277. doi: 10.1056/NEJMp1311405

2. R Sahathevan. Chapter 18 - Dementia : An Overview of Risk Factors. Diet \& Nutrition in Dementia \& Cognitive Decline 2015:187-198. doi: https://doi. org/10.1016/B978-0-12-407824-6.00018-5

3. C Patterson. The World Alzheimer Report 2018. The state of the art of dementia 
research: New frontiers. London: Alzheimer's Disease International, 2018.

4. AFG Cicero, F Fogacci, M Banach. Botanicals and phytochemicals active on cognitive decline: The clinical evidence. Pharmacol Res 2018;130:204-212. doi: 10.1016/j. phrs.2017.12.029

5. S Rajaram, J Jones, GJ Lee. Plant-Based Dietary Patterns, Plant Foods, and AgeRelated Cognitive Decline. Adv Nutr 2019;10(Suppl_4):S422-S436. doi: 10.1093/ advances/nmz081

6. SM Poulose, MG Miller, T Scott, et al. Nutritional Factors Affecting Adult Neurogenesis and Cognitive Function. Adv Nutr 2017;8(6):804-811. doi: 10.3945/ an.117.016261

7. P Hajieva. The Effect of Polyphenols on Protein Degradation Pathways: Implications for Neuroprotection. Molecules 2017;22(1) doi: 10.3390/molecules22010159

8. G Mazzanti, S Di Giacomo. Curcumin and Resveratrol in the Management of Cognitive Disorders: What is the Clinical Evidence? Molecules 2016;21(9) doi: 10.3390/molecules 21091243

9. RS Turner, RG Thomas, S Craft, et al. A randomized, double-blind, placebo-controlled trial of resveratrol for Alzheimer disease. Neurology 2015;85(16):1383-1391. doi: 10.1212/WNL.0000000000002035

10. JM Ringman, SA Frautschy, E Teng, et al. Oral curcumin for Alzheimer's disease: tolerability and efficacy in a 24-week randomized, double blind, placebo-controlled study. Alzheimers Res Ther 2012;4(5):43. doi: 10.1186/alzrt146

11 A Crozier, IB Jaganath, MN Clifford. Dietary phenolics: chemistry, bioavailability and effects on health. Nat Prod Rep 2009;26(8):1001-1043. doi: 10.1039/b802662a

12. PC Guest. Reviews on New Drug Targets in Age-Related Disorders. Advances in Experimental Medicine and Biology 2020 https://doi.org/10.1007/978-3-030-4266755

13 CG Fraga, KD Croft, DO Kennedy, et al. The effects of polyphenols and other bioactives on human health. Food Funct 2019;10(2):514-528. doi: 10.1039/c8fo01997e

14. C Colizzi. The protective effects of polyphenols on Alzheimer's disease: A systematic review. Alzheimers Dement (N Y) 2019;5:184-196. doi: 10.1016/j.trci.2018.09.002

15 C Spagnuolo, M Napolitano, I Tedesco, et al. Neuroprotective Role of Natura Polyphenols. Curr Top Med Chem 2016;16(17):1943-1950. doi: 10.2174/1568026616 666160204122449

16. E Nurk, H Refsum, CA Drevon, et al. Intake of flavonoid-rich wine, tea, and chocolate by elderly men and women is associated with better cognitive test performance. J Nutr 2009;139(1):120-127. doi: 10.3945/jn.108.095182

17 C Butchart, J Kyle, G McNeill, et al. Flavonoid intake in relation to cognitive function in later life in the Lothian Birth Cohort 1936. Br J Nutr 2011;106(1):141-148. doi: $10.1017 /$ S0007114510005738

18 S Kalmijn, EJ Feskens, LJ Launer, et al. Polyunsaturated fatty acids, antioxidants, and cognitive function in very old men. Am J Epidemiol 1997;145(1):33-41. doi: 10.1093/ oxfordjournals.aje.a009029

19 D Laurin, KH Masaki, DJ Foley, et al. Midlife dietary intake of antioxidants and risk of late-life incident dementia: the Honolulu-Asia Aging Study. Am J Epidemio 2004;159(10):959-967. doi: 10.1093/aje/kwh124

20 MJ Engelhart, MI Geerlings, A Ruitenberg, et al. Dietary intake of antioxidants and risk of Alzheimer disease. JAMA 2002;287(24):3223-3229. doi: 10.1001/ jama.287.24.3223

21 EE Devore, F Grodstein, FJ van Rooij, et al. Dietary antioxidants and long-term risk of dementia. Arch Neurol 2010;67(7):819-825. doi: 10.1001/archneurol.2010.144

22 D Commenges, V Scotet, S Renaud, et al. Intake of flavonoids and risk of dementia Eur J Epidemiol 2000;16(4):357-363. doi: 10.1023/a:1007614613771

23 E Shishtar, GT Rogers, JB Blumberg, et al. Long-term dietary flavonoid intake an risk of Alzheimer disease and related dementias in the Framingham Offspring Cohort. Am J Clin Nutr 2020;112(2):343-353. doi: 10.1093/ajen/nqaa079

24 EE Devore, JH Kang, MM Breteler, et al. Dietary intakes of berries and flavonoids in relation to cognitive decline. Ann Neurol 2012;72(1):135-143. doi: 10.1002/ana.23594

25 L Letenneur, C Proust-Lima, A Le Gouge, et al. Flavonoid intake and cognitive decline over a 10-year period. Am J Epidemiol 2007;165(12):1364-1371. doi: 10.1093/aje/ kwm036

26 DR Doerge, DM Sheehan. Goitrogenic and estrogenic activity of soy isoflavones Environ Health Perspect 2002;110 Suppl 3:349-353. doi: 10.1289/ehp.02110s3349

27 FM Sacks, A Lichtenstein, L Van Horn, et al. Soy protein, isoflavones, and cardiovascular health: an American Heart Association Science Advisory for professionals from the Nutrition Committee. Circulation 2006;113(7):1034-1044. doi: 10.1161/CIRCULATIONAHA.106.171052

28 M Igase, K Igase, Y Tabara, et al. Cross-sectional study of equol producer status and cognitive impairment in older adults. Geriatr Gerontol Int 2017;17(11):2103-2108. doi: 10.1111/ggi.13029

29 E Hogervorst, T Sadjimim, A Yesufu, et al. High tofu intake is associated with worse memory in elderly Indonesian men and women. Dement Geriatr Cogn Disord 2008;26(1):50-57. doi: 10.1159/000141484

$30 \mathrm{X} \mathrm{Xu}, \mathrm{S}$ Xiao, TB Rahardjo, et al. Tofu intake is associated with poor cognitive performance among community-dwelling elderly in China. J Alzheimers Dis 2015;43(2):669-675. doi: 10.3233/JAD-141593

31. LR White, H Petrovitch, GW Ross, et al. Brain aging and midlife tofu consumption. J Am Coll Nutr 2000;19(2):242-255. doi: 10.1080/07315724.2000.10718923
32. PF Cheng, JJ Chen, XY Zhou, et al. Do soy isoflavones improve cognitive function in postmenopausal women? A meta-analysis. Menopause 2015;22(2):198-206. doi: 10.1097/GME.0000000000000290

33. S Kreijkamp-Kaspers, L Kok, DE Grobbee, et al. Effect of soy protein containing isoflavones on cognitive function, bone mineral density, and plasma lipids in postmenopausal women: a randomized controlled trial. JAMA 2004;292(1):65-74. doi: 10.1001/jama.292.1.65

34. LR Fournier, TA Ryan Borchers, LM Robison, et al. The effects of soy milk and isoflavone supplements on cognitive performance in healthy, postmenopausal women. J Nutr Health Aging 2007;11(2):155-164. https://www.researchgate.net/ publication/6392422, and the PMID: 17435957.

35. VW Henderson, JA St John, HN Hodis, et al. Long-term soy isoflavone supplementation and cognition in women: a randomized, controlled trial. Neurology 2012;78(23):1841-1848. doi: 10.1212/WNL.0b013e318258f822

36. S Basaria, A Wisniewski, K Dupree, et al. Effect of high-dose isoflavones on cognition, quality of life, androgens, and lipoprotein in post-menopausal women. J Endocrinol Invest 2009;32(2):150-155. doi: 10.1007/BF03345705

37. SC Ho, AS Chan, YP Ho, et al. Effects of soy isoflavone supplementation on cognitive function in Chinese postmenopausal women: a double-blind, randomized, controlled trial. Menopause 2007;14(3 Pt 1):489-499. doi: 10.1097/GME.0b013e31802c4f4f

38. RF Santos-Galduroz, JC Galduroz, RL Facco, et al. Effects of isoflavone on the learning and memory of women in menopause: a double-blind placebo-controlled study. Braz J Med Biol Res 2010;43(11):1123-1126. doi: 10.1590/s0100879x2010007500104

39. ML Casini, G Marelli, E Papaleo, et al. Psychological assessment of the effects of treatment with phytoestrogens on postmenopausal women: a randomized, doubleblind, crossover, placebo-controlled study. Fertil Steril 2006;85(4):972-978. doi: 10.1016/j.fertnstert.2005.09.048

40. D Kritz-Silverstein, D Von Muhlen, E Barrett-Connor, et al. Isoflavones and cognitive function in older women: the SOy and Postmenopausal Health In Aging (SOPHIA) Study. Menopause 2003;10(3):196-202. doi: 10.1097/00042192-200310030-00004

41. SE File, DE Hartley, S Elsabagh, et al. Cognitive improvement after 6 weeks of soy supplements in postmenopausal women is limited to frontal lobe function. Menopause 2005;12(2):193-201. doi: 10.1097/00042192-200512020-00014

42. R Duffy, H Wiseman, SE File. Improved cognitive function in postmenopausal women after 12 weeks of consumption of a soya extract containing isoflavones. Pharmacol Biochem Behav 2003;75(3):721-729. doi: 10.1016/s0091-3057(03)00116-3

43. AA Thorp, N Sinn, JD Buckley, et al. Soya isoflavone supplementation enhances spatial working memory in men. Br J Nutr 2009;102(9):1348-1354. doi: 10.1017/ S0007114509990201

44. SE File, N Jarrett, E Fluck, et al. Eating soya improves human memory Psychopharmacology (Berl) 2001;157(4):430-436. doi: 10.1007/s002130100845

45. E Hogervorst, F Mursjid, D Priandini, et al. Borobudur revisited: soy consumption may be associated with better recall in younger, but not in older, rural Indonesian elderly. Brain Res 2011;1379:206-212. doi: 10.1016/j.brainres.2010.10.083

46. CE Gleason, CM Carlsson, JH Barnet, et al. A preliminary study of the safety, feasibility and cognitive efficacy of soy isoflavone supplements in older men and women. Age Ageing 2009;38(1):86-93. doi: 10.1093/ageing/afn227

47. D Chen, SB Wan, H Yang, et al. EGCG, green tea polyphenols and their synthetic analogs and prodrugs for human cancer prevention and treatment. Adv Clin Chem 2011;53:155-177. doi: 10.1016/b978-0-12-385855-9.00007-2

48. QP Ma, C Huang, QY Cui, et al. Meta-Analysis of the Association between Tea Intake and the Risk of Cognitive Disorders. PLoS One 2016;11(11):e0165861. doi: 10.1371/ journal.pone.0165861

49. X Liu, X Du, G Han, et al. Association between tea consumption and risk of cognitive disorders: A dose-response meta-analysis of observational studies. Oncotarget 2017;8(26):43306-43321. doi: 10.18632/oncotarget.17429

50. EL Wightman, CF Haskell, JS Forster, et al. Epigallocatechin gallate, cerebral blood flow parameters, cognitive performance and mood in healthy humans: a double-blind, placebo-controlled, crossover investigation. Hum Psychopharmacol 2012;27(2):177186. doi: 10.1002/hup.1263

51. K Ide, H Yamada, N Takuma, et al. Green tea consumption affects cognitive dysfunction in the elderly: a pilot study. Nutrients 2014;6(10):4032-4042. doi: 10.3390/nu6104032

52. K Ide, H Yamada, N Takuma, et al. Effects of green tea consumption on cognitive dysfunction in an elderly population: a randomized placebo-controlled study. Nutr 2016;15(1):49. doi: 10.1186/s12937-016-0168-7

53. Y Baba, S Inagaki, S Nakagawa, et al. Effect of Daily Intake of Green Tea Catechins on Cognitive Function in Middle-Aged and Older Subjects: A Randomized, PlaceboControlled Study. Molecules 2020;25(18) doi: 10.3390/molecules25184265

54. AN Sokolov, MA Pavlova, S Klosterhalfen, et al. Chocolate and the brain: neurobiological impact of cocoa flavanols on cognition and behavior. Neurosc Biobehav Rev 2013;37(10 Pt 2):2445-2453. doi: 10.1016/j.neubiorev.2013.06.013

55. GE Crichton, MF Elias, A Alkerwi. Chocolate intake is associated with better cognitive function: The Maine-Syracuse Longitudinal Study. Appetite 2016;100:126-132. doi: 10.1016/j.appet.2016.02.010

56. RS Calabro, MC De Cola, G Gervasi, et al. The Efficacy of Cocoa Polyphenols in the 
Treatment of Mild Cognitive Impairment: A Retrospective Study. Medicina (Kaunas) 2019;55(5) doi: 10.3390/medicina55050156

57. A Moreira, MJ Diogenes, A de Mendonca, et al. Chocolate Consumption is Associated with a Lower Risk of Cognitive Decline. J Alzheimers Dis 2016;53(1):85-93. doi: 10.3233/JAD-160142

58. AB Scholey, SJ French, PJ Morris, et al. Consumption of cocoa flavanols results in acute improvements in mood and cognitive performance during sustained mental effort. J Psychopharmacol 2010;24(10):1505-1514. doi: 10.1177/0269881109106923

59. DT Field, CM Williams, LT Butler. Consumption of cocoa flavanols results in an acute improvement in visual and cognitive functions. Physiol Behav 2011;103(3-4):255-260. doi: 10.1016/j.physbeh.2011.02.013

60. AM Brickman, UA Khan, FA Provenzano, et al. Enhancing dentate gyrus function with dietary flavanols improves cognition in older adults. Nat Neurosci 2014;17(12):1798-1803. doi: 10.1038/nn.3850

61. D Mastroiacovo, C Kwik-Uribe, D Grassi, et al. Cocoa flavanol consumption improves cognitive function, blood pressure control, and metabolic profile in elderly subjects: the Cocoa, Cognition, and Aging (CoCoA) Study--a randomized controlled trial. Am J Clin Nutr 2015;101(3):538-548. doi: 10.3945/ajen.114.092189

62. G Desideri, C Kwik-Uribe, D Grassi, et al. Benefits in cognitive function, blood pressure, and insulin resistance through cocoa flavanol consumption in elderly subjects with mild cognitive impairment: the Cocoa, Cognition, and Aging (CoCoA) study. Hypertension 2012;60(3):794-801. doi: 10.1161/HYPERTENSIONAHA.112.193060

63. MP Pase, AB Scholey, A Pipingas, et al. Cocoa polyphenols enhance positive mood states but not cognitive performance: a randomized, placebo-controlled trial. J Psychopharmacol 2013;27(5):451-458. doi: 10.1177/0269881112473791

64. C Manach, A Scalbert, C Morand, et al. Polyphenols: food sources and bioavailability Am J Clin Nutr 2004;79(5):727-747. doi: 10.1093/ajen/79.5.727

65. Q Dai, AR Borenstein, Y Wu, et al. Fruit and vegetable juices and Alzheimer's disease: the Kame Project. Am J Med 2006;119(9):751-759. doi: 10.1016/j. amjmed.2006.03.045

66. S Peneau, P Galan, C Jeandel, et al. Fruit and vegetable intake and cognitive function in the SU.VI.MAX 2 prospective study. Am J Clin Nutr 2011;94(5):1295-1303. doi: 10.3945/ajen.111.014712

67. P Agarwal, TM Holland, Y Wang, et al. Association of Strawberries and Anthocyanidin Intake with Alzheimer's Dementia Risk. Nutrients 2019;11(12)doi: 10.3390/ nu 11123060

68. MC Morris, DA Evans, CC Tangney, et al. Associations of vegetable and fruit consumption with age-related cognitive change. Neurology 2006;67(8):1370-1376. doi: 10.1212/01.wnl.0000240224.38978.d8

69. AC Nooyens, HB Bueno-de-Mesquita, MP van Boxtel, et al. Fruit and vegetable intake and cognitive decline in middle-aged men and women: the Doetinchem Cohort Study. Br J Nutr 2011;106(5):752-761 . doi: 10.1017/S0007114511001024

70. MH Alharbi, DJ Lamport, GF Dodd, et al. Flavonoid-rich orange juice is associated with acute improvements in cognitive function in healthy middle-aged males. Eur J Nutr 2016;55(6):2021-2029. doi: 10.1007/s00394-015-1016-9

71. CF Haskell-Ramsay, RC Stuart, EJ Okello, et al. Cognitive and mood improvements following acute supplementation with purple grape juice in healthy young adults. Eur J Nutr 2017;56(8):2621-2631. doi: 10.1007/s00394-017-1454-7

72. DJ Lamport, D Pal, AL Macready, et al. The effects of flavanone-rich citrus juice on cognitive function and cerebral blood flow: an acute, randomised, placebo-controlled cross-over trial in healthy, young adults. Br J Nutr 2016;116(12):2160-2168. doi: 10.1017/S000711451600430X

73. KM Keane, CF Haskell-Ramsay, RC Veasey, et al. Montmorency Tart cherries (Prunus cerasus L.) modulate vascular function acutely, in the absence of improvement in cognitive performance. Br J Nutr 2016;116(11):1935-1944. doi: 10.1017/ S0007114516004177

74. MG Miller, DA Hamilton, JA Joseph, et al. Dietary blueberry improves cognition among older adults in a randomized, double-blind, placebo-controlled trial. Eur J Nut 2018;57(3):1169-1180. doi: 10.1007/s00394-017-1400-8

75. JL Bowtell, Z Aboo-Bakkar, ME Conway, et al. Enhanced task-related brain activation and resting perfusion in healthy older adults after chronic blueberry supplementation. Appl Physiol Nutr Metab 2017;42(7):773-779. doi: 10.1139/apnm-2016-0550

76. R Krikorian, MD Shidler, TA Nash, et al. Blueberry supplementation improves memory in older adults. J Agric Food Chem 2010;58(7):3996-4000. doi: 10.1021/ jf9029332

77. EL Boespflug, JC Eliassen, JA Dudley, et al. Enhanced neural activation with blueberry supplementation in mild cognitive impairment. Nutr Neurosci 2018;21(4):297-305. doi: 10.1080/1028415X.2017.1287833

78. RK McNamara, W Kalt, MD Shidler, et al. Cognitive response to fish oil, blueberry, and combined supplementation in older adults with subjective cognitive impairment Neurobiol Aging 2018;64:147-156. doi: 10.1016/j.neurobiolaging.2017.12.003

79. DJ Lamport, CL Lawton, $\mathrm{N}$ Merat, et al. Concord grape juice, cognitive function, and driving performance: a 12-wk, placebo-controlled, randomized crossover trial in mothers of preteen children. Am J Clin Nutr 2016;103(3):775-783. doi: 10.3945/ ajcn.115.114553

80. R Krikorian, TA Nash, MD Shidler, et al. Concord grape juice supplementation improves memory function in older adults with mild cognitive impairment. Br J Nut
2010;103(5):730-734. doi: 10.1017/S0007114509992364

81. R Krikorian, EL Boespflug, DE Fleck, et al. Concord grape juice supplementation and neurocognitive function in human aging. J Agric Food Chem 2012;60(23):5736-5742. doi: $10.1021 / \mathrm{jf} 300277 \mathrm{~g}$

82. RJ Kean, DJ Lamport, GF Dodd, et al. Chronic consumption of flavanone-rich orange juice is associated with cognitive benefits: an 8-wk, randomized, double-blind, placebo-controlled trial in healthy older adults. Am J Clin Nutr 2015;101(3):506-514 doi: $10.3945 /$ ajen. 114.088518

83. SY Bookheimer, BA Renner, A Ekstrom, et al. Pomegranate juice augments memory and FMRI activity in middle-aged and older adults with mild memory complaints. Evid Based Complement Alternat Med 2013;2013:946298. doi: 10.1155/2013/946298

84. A Nilsson, I Salo, M Plaza, et al. Effects of a mixed berry beverage on cognitive functions and cardiometabolic risk markers; A randomized cross-over study in healthy older adults. PLoS One 2017;12(11):e0188173. doi: 10.1371/journal.pone.0188173

85. H Hatcher, R Planalp, J Cho, et al. Curcumin: from ancient medicine to current clinical trials. Cell Mol Life Sci 2008;65(11):1631-1652. doi: 10.1007/s00018-008-7452-4

86. RA DiSilvestro, E Joseph, S Zhao, et al. Diverse effects of a low dose supplement of lipidated curcumin in healthy middle aged people. Nutr J 2012;11:79. doi 10.1186/1475-2891-11-79

87. KH Cox, A Pipingas, AB Scholey. Investigation of the effects of solid lipid curcumin on cognition and mood in a healthy older population. J Psychopharmacol 2015;29(5):642-651. doi: 10.1177/0269881114552744

88. MS Lee, ML Wahlqvist, YC Chou, et al. Turmeric improves post-prandial working memory in pre-diabetes independent of insulin. Asia Pac J Clin Nutr 2014;23(4):581591. doi: 10.6133/apjen.2014.23.4.24

89. GW Small, P Siddarth, Z Li, et al. Memory and Brain Amyloid and Tau Effects of a Bioavailable Form of Curcumin in Non-Demented Adults: A Double-Blind, Placebo-Controlled 18-Month Trial. Am J Geriatr Psychiatry 2018;26(3):266-277. doi: 10.1016/j.jagp.2017.10.010

90. SR Rainey-Smith, BM Brown, HR Sohrabi, et al. Curcumin and cognition: randomised, placebo-controlled, double-blind study of community-dwelling older adults. Br J Nutr 2016;115(12):2106-2113. doi: 10.1017/S0007114516001203

91. B Salehi, AP Mishra, M Nigam, et al. Resveratrol: A Double-Edged Sword in Health Benefits. Biomedicines 2018;6(3) doi: 10.3390/biomedicines6030091

92. J Shi, M He, J Cao, et al. The comparative analysis of the potential relationship between resveratrol and stilbene synthase gene family in the development stages of grapes (Vitis quinquangularis and Vitis vinifera). Plant Physiol Biochem 2014;74:2432. doi: 10.1016/j.plaphy.2013.10.021

93. BC Akinwumi, KM Bordun, HD Anderson. Biological Activities of Stilbenoids. Int Mol Sci 2018;19(3) doi: 10.3390/ijms19030792

94. DO Kennedy, EL Wightman, JL Reay, et al. Effects of resveratrol on cerebral blood flow variables and cognitive performance in humans: a double-blind, placebocontrolled, crossover investigation. Am J Clin Nutr 2010;91(6):1590-1597. doi: $10.3945 /$ ajen.2009.28641

95. EL Wightman, JL Reay, CF Haskell, et al. Effects of resveratrol alone or in combination with piperine on cerebral blood flow parameters and cognitive performance in human subjects: a randomised, double-blind, placebo-controlled, crossover investigation. Br J Nutr 2014;112(2):203-213. doi: 10.1017/S0007114514000737

96. JJ Johnson, M Nihal, IA Siddiqui, et al. Enhancing the bioavailability of resveratrol by combining it with piperine. Mol Nutr Food Res 2011;55(8):1169-1176. doi: 10.1002/ mnfr.201100117

97. RH Wong, D Raederstorff, PR Howe. Acute Resveratrol Consumption Improves Neurovascular Coupling Capacity in Adults with Type 2 Diabetes Mellitus. Nutrients 2016;8(7) doi: 10.3390/nu8070425

98. EL Wightman, CF Haskell-Ramsay, JL Reay, et al. The effects of chronic transresveratrol supplementation on aspects of cognitive function, mood, sleep, health and cerebral blood flow in healthy, young humans. Br J Nutr 2015;114(9):1427-1437. doi: $10.1017 /$ S0007114515003037

99. C Moran, A Scotto di Palumbo, J Bramham, et al. Effects of a Six-Month MultiIngredient Nutrition Supplement Intervention of Omega-3 Polyunsaturated Fatty Acids, vitamin D, Resveratrol, and Whey Protein on Cognitive Function in Older Adults: A Randomised, Double-Blind, Controlled Trial. J Prev Alzheimers Dis 2018;5(3):175-183. doi: 10.14283/jpad.2018.11

100. SD Anton, N Ebner, JM Dzierzewski, et al. Effects of 90 Days of Resveratro Supplementation on Cognitive Function in Elders: A Pilot Study. J Altern Complement Med 2018;24(7):725-732. doi: 10.1089/acm.2017.0398

101. AV Witte, L Kerti, DS Margulies, et al. Effects of resveratrol on memory performance, hippocampal functional connectivity, and glucose metabolism in healthy older adults. J Neurosci 2014:34(23):7862-7870. doi: 10.1523/JNEUROSCI.0385-14.2014

102. S Huhn, F Beyer, R Zhang, et al. Effects of resveratrol on memory performance, hippocampus connectivity and microstructure in older adults - A randomized controlled trial. Neuroimage 2018;174:177-190. doi: 10.1016/j neuroimage 2018.03 .023

103. T Kobe, AV Witte, A Schnelle, et al. Impact of Resveratrol on Glucose Control, Hippocampal Structure and Connectivity, and Memory Performance in Patients with Mild Cognitive Impairment. Front Neurosci 2017;11:105. doi: 10.3389/ fnins.2017.00105 
104. HM Evans, PR Howe, RH Wong. Effects of Resveratrol on Cognitive Performance, Mood and Cerebrovascular Function in Post-Menopausal Women; A 14-Week Randomised Placebo-Controlled Intervention Trial. Nutrients 2017;9(1) doi: 10.3390/ nu9010027

105. HM Evans, PR Howe, RH Wong. Clinical Evaluation of Effects of Chronic Resveratrol Supplementation on Cerebrovascular Function, Cognition, Mood, Physical Function and General Well-Being in Postmenopausal Women-Rationale and Study Design. Nutrients 2016;8(3):150. doi: 10.3390/nu8030150

106. S Kreijkamp-Kaspers, L Kok, DE Grobbee, et al. Dietary phytoestrogen intake and cognitive function in older women. J Gerontol A Biol Sci Med Sci 2007;62(5):556562. doi: 10.1093/gerona/62.5.556

107. OH Franco, H Burger, CE Lebrun, et al. Higher dietary intake of lignans is associated with better cognitive performance in postmenopausal women. J Nutr 2005;135(5):1190-1195. doi: 10.1093/jn/135.5.1190

108. AC Nooyens, IE Milder, BM van Gelder, et al. Diet and cognitive decline at middle age: the role of antioxidants. Br J Nutr 2015;113(9):1410-1417. doi: 10.1017/ S0007114515000720

109. M Rabassa, A Cherubini, R Zamora-Ros, et al. Low Levels of a Urinary Biomarker of Dietary Polyphenol Are Associated with Substantial Cognitive Decline over a 3-Year Period in Older Adults: The Invecchiare in Chianti Study. J Am Geriatr Soc 2015;63(5):938-946. doi: 10.1111/jgs.13379

110. E Kesse-Guyot, L Fezeu, VA Andreeva, et al. Total and specific polyphenol intakes in midlife are associated with cognitive function measured 13 years later. J Nutr 2012;142(1):76-83. doi: 10.3945/jn.111.144428

111. S Lefevre-Arbogast, D Gaudout, J Bensalem, et al. Pattern of polyphenol intake and the long-term risk of dementia in older persons. Neurology 2018;90(22):e1979-e1988. doi: 10.1212/WNL.0000000000005607

112. J Lee, $\mathrm{N}$ Torosyan, DH Silverman. Examining the impact of grape consumption on brain metabolism and cognitive function in patients with mild decline in cognition: A double-blinded placebo controlled pilot study. Exp Gerontol 2017;87(Pt A):121-128. doi: 10.1016/j.exger.2016.10.004
113. PJ Joris, RP Mensink, TC Adam, et al. Cerebral Blood Flow Measurements in Adults: A Review on the Effects of Dietary Factors and Exercise. Nutrients 2018;10(5) doi: 10.3390/nu10050530

114. M Ayaz, A Sadiq, M Junaid, et al. Flavonoids as Prospective Neuroprotectants and Their Therapeutic Propensity in Aging Associated Neurological Disorders. Front Aging Neurosci 2019;11:155. doi: 10.3389/fnagi.2019.00155

115. N Raz, KM Rodrigue, JD Acker. Hypertension and the brain: vulnerability of the prefrontal regions and executive functions. Behav Neurosci 2003;117(6):1169-1180. doi: 10.1037/0735-7044.117.6.1169

116. JP Spencer. The impact of flavonoids on memory: physiological and molecular considerations. Chem Soc Rev 2009;38(4):1152-1161. doi: 10.1039/b800422f

117. AL Macready, OB Kennedy, JA Ellis, et al. Flavonoids and cognitive function: a review of human randomized controlled trial studies and recommendations for future studies. Genes Nutr 2009;4(4):227-242. doi: 10.1007/s12263-009-0135-4

118. JM Smoliga, O Blanchard. Enhancing the delivery of resveratrol in humans: if low bioavailability is the problem, what is the solution? Molecules 2014;19(11):17154 17172. doi: 10.3390/molecules 191117154

119. K Nakagawa, K Nakayama, M Nakamura, et al. Effects of co-administration of tea epigallocatechin-3-gallate (EGCG) and caffeine on absorption and metabolism of EGCG in humans. Biosci Biotechnol Biochem 2009;73(9):2014-2017. doi: 10.1271/ bbb. 90195

120. C Schiborr, A Kocher, D Behnam, et al. The oral bioavailability of curcumin from micronized powder and liquid micelles is significantly increased in healthy humans and differs between sexes. Mol Nutr Food Res 2014;58(3):516-527. doi: 10.1002/ mnfr.201300724

How to cite this article: W. Yang, K. Cui, X. Li, et al. Effect of Polyphenols on Cognitive Function: Evidence from Population-Based Studies and Clinical Trials. J Nutr Health Aging. 2021;25(10):1190-1204, http://dx.doi.org/10.1007/s12603-021-1685-4 